\title{
Mental cruelty: an extent of alchemy of feelings?
}

\section{Proceeding}

In a popular Hindi T.V serial, a person tells a lady that marriage is only a temporary attachment, to which the lady retorts that she believes in one life, one marriage. In India, marriage and family dominate the life of women. One sociologist Susan Wadley after analysing the identity of women in different folktale, myths, and legends rooted in our culture, observed that the Indian woman is constantly made to adopt contradictory roles i.e. the nurturing roles as daughters, mothers, wives, and as daughter-in-laws, and the stereotyped role of a weak and helpless woman. The latter is fostered to ensure complete dependence on the male sex. Consequently, the constant movement from strength to passivity leads to enormous stress placing the woman's mental health under constant threat. The primary duty of the woman is to be subservient to the husband/ his relatives and her children. An admirable sentiment from which there has been a gradual shift in perception by individuals of both genders. An increasing number of divorce cases are taking place on grounds of 'mental cruelty' and form time to time, some of these divorce cases reach the Supreme Court. ${ }^{1}$ Some of the Court's views on this are placed for general information particularly, of Civil Society.

Straightaway, the Court has observed that 'cruelty has not been defined, and it has been used in relation to human conduct or human behaviour'. (VinitSaxena V. PankajPandit (2006) 3SCC 778). On the same subject of 'mental cruelty', the Court in another judgement states 'No uniform standard can ever be laid down for guidance, yet we deem it appropriate to enumerate some instances of human behaviour which may be relevant in dealing with cases of mental cruelty'. Certain instances were indicated with the remark that they are only illustrative and not exhaustive (Samar Ghosh V. Jaya Ghosh (2007) 4 SCC 511). It seems that the insertion of Sec.113 IEA and Sec. 498A IPC did not seem to have improved the lot of women experiencing domestic violence, battered women, given that the judiciary has such 'stringent' methods to measure cruelty against women. ${ }^{2}$ The rate of conviction in cases of domestic violence, and mental cruelty is rarely accepted as legally valid in cases involving domestic violence, unless they are accompanied by physical violence. ${ }^{3}$ Clearly, in civil law, where mental cruelty is a ground for divorce, the ambiguity of the term is used to absolve men and to chastise women. Stringent rules of wifely behaviour as set by the Hon'ble judge's perception of religious law and tradition are used to measure the rightness of women's

'http://www.hindustantimes.com/sex-and-relationships/how-and-whynumber-of-young-indian-couples-getting-divorced-has-risen-sharply/storymEuaEoviW40d6slLZbGu6J.html

${ }^{2}$ Prior to the insertion of S498A, the section often used for wife murders was S300 IPC, 1860, which states that culpable homicide is not murder, 'if the offender, whilst deprived of the power of self-control by grave and sudden provocation, causes the death of the person, who gave the provocation.' The test for provocation was the provocation must have been sufficient to anger 'a reasonable man'. BOOK Indian Feminisms: Law, Patriarchies and Violence in India GeetanjaliGangoli, University of Bristol, UK.

${ }^{3}$ In one cases, where the wife had committed suicide since hed husband was involved with another woman, the judge ruled that the act of the husband keeping a mistress was not an act that could provoke a woman to commit suicide, see Babu Shankar Jadhav v. State of Maharashtra. SC 172/88 cited in Seshu and Bhonsalend, 48.

\author{
Volume 4 Issue I - 2017
}

\author{
Tulishree Pradhan \\ Department of Law, KIIT University, India
}

Correspondence: Tulishree Pradhan, KIIT School of Law, KIIT University, PrasantiVihar, Patia Bhubaneswar - 751024, Odisha, India, Email rainy94@gmail.com

Received: January 12, 2017| Published: January 17, 2017

actions, while neglect and physical violence by men are condoned. The above cases were followed by a Bench of the Supreme Court in VidhyaViswanathan V. KartikBalakrishnan (2004 (II) OLR (SC) 907 and an illustrative, not exhaustive list was drawn up to show what does and what doesn't constitute mental cruelty.

This is shown below:

\section{A. What constitute mental cruelty?}

i. On consideration of complete matrimonial life of the parties, acute mental pain, agony and suffering as would not make possible for the parties to live with each other.

ii. On appraisal of the entire matrimonial life of the parties it becomes abundantly clear that the wronged party cannot reasonably be asked to put up with such conduct and continue to live with the other party.

iii. Mental cruelty is a state of mind. The feeling of deep anguish, disappointment, frustration in one spouse caused by the conduct of the other for a long time.

iv. A sustained course of abusing and humiliating treatment calculated to torture, discommode or render miserable the life of the spouse. The treatment complained of and the resultant danger or apprehension must be very grave, substantial and weighty.

v. Sustained reprehensible conduct, studied neglect, indifference or total departure from the normal standard of conjugal kindness, causing injury to mental health or deriving sadistic pleasure from the above.

vi. Persistent ill conduct for a fairly lengthy period where the relationship has deteriorated to an extent that because of the acts and behaviour of a spouse, the wronged party finds it extremely difficult to life with the other party.

vii. Husband submits himself to a sterilization operation without medical reasons and without the consent or knowledge of the wife undergoes vasectomy or abortion without medical reason or without the consent or knowledge of the husband.

viii. Unilateral decision of refusal to have intercourse for a 
considerable period without there being any physical incapacity or valid reason.

ix. Unilateral decision of either husband or wife after marriage not to have a child from the marriage.

B. What does not amount to mental cruelty?

i. Mere trivial irritations, quarrels, normal wear and tear of married life which happens in day-to-day life.

ii. Conduct must be more than jealously, selfishness, possessiveness which causes, unhappiness, dissatisfaction or emotional upset.

iii. Mere coldness or lack of affection, frequent rudeness of language, petulance of manner, indifference and neglect unless it reaches such a degree that it makes the married life of spouse absolutely intolerable.
In stating the above illustrative cases, the Supreme Court has emphasized that the whole married life must be considered, every case should be carefully examined because termination of a marriage is a serious irreversible step which should not be lightly dealt with.

\section{Acknowledgments}

None.

\section{Conflicts of interest}

The author declares there are no conflicts of interest. 